\title{
VALUASI EKONOMI NILAI GUNA TIDAK LANGSUNG KAWASAN MANGROVE DI KELURAHAN SETAPUK BESAR KOTA SINGKAWANG
}

\author{
(Economic Valuation of mangrove areas indirect use value in Setapuk Besar village
} Singkawang)

\author{
Iphon Nandu , Emi Roslinda , Gusti Hardiansyah \\ Fakultas Kehutanan Universitas Tanjungpura Pontianak. J1. Daya Nasional Pontianak 78124 \\ Email : iphonnnandu@yahoo.com
}

\begin{abstract}
This research to determine the indirect use value of coastal protection by planting mangroves in Setapuk Besar Village and comparing the benefits between the development of coastal protection in biological and physical. research was carried out from July-August 2018. this study used descriptive quantitative method. Analyze the data using the replacement cost method. Interview was carried out only with key respondents who as acted the chairman of the SPM (Surya Perdana Mandiri) association in Setapuk Besar. The results showed that total costs incurred are based on planting, protection, work wages and inventory activities of Rp. 270.182.000 there was 4 (four) financing according to the object of expenditure in the mangrove return activities (Enrichment). The cost of returning mangroves is much cheaper than the cost of making breakwaters other than that the benefits of mangroves are far more than building protection with Breakwater.
\end{abstract}

Keyword: Economic valuation, Mangrove, replacement cost

\section{PENDAHULUAN}

Kelestarian hutan mangrove sangat perlu diperhatikan mengingat perannya yang besar untuk kehidupan disekitarnya sehingga ekosistem mangrove dapat dikatakan sebagai ekosistem yang produktif sesuai dengan fungsi dan kandungannya. Jika hutan mangrove menjadi rusak secara fisik, maka segala komponen biotik dan abiotik didalamnya selain itu dapat terjadi pengikisan daerah pesisir (erosi).

Saat ini pemerintah yang daerahnya memiliki pesisir pantai mulai memberi perhatian secara intensif terhadap ancaman abrasi pantai. Penyelamatan garis pantai dari abrasi dilakukan dengan berbagai macam cara diantaranya dengan pembagunan alat pemecah ombak (APO) dan pengayaan dengan mangrove. Upaya dalam kegiatan pengayaan kawasan mangrove menyangkut beberapa aspek penting, diantaranya tenaga kerja, biaya, dan waktu yang terbuang dalam pengelolaanya, sehingga menjadikan mangrove menjadi bernilai untuk masa mendatang (futur value) (Harahab. 2010).

Secara garis besar dapat kita simpulkan bahwa kegiatan pengayaan membutuhkan biaya dan waktu dalam kegiatanya maka perlu dilakukan penilaian. Harahab (2010) menyatakan penilaian dengan menggunakan konsep valuasi ekonomi akan membantu dalam mengetahui bahwa ekosistem tersebut memiliki nilai yang sangat tinggi untuk 
kehidupan. Menyadari pentingnya kawasan hutan mangrove, maka diperlukan penelitian untuk mengetahui seberapa besar nilai manfaat ekonomi guna tidak langsung yang terkandung dari hutan mangrove di kelurahan Setapuk Besar terhadap kegiatan pengayaan yang dilakukan.

Tujuan dari penelitian ini adalah untuk mengetahui nilai guna tidak langsung terhadap perlindungan pantai dengan penanaman mangrove kelurahan Setapuk Besar dan Membandingkan manfaat antara pembangunan perlindungan pantai dengan cara biologi dan fisik. Hasilnya diharapkan bisa dijadikan informasi bagi masyarakat maupun pemerintah dalam pengambilan keputusan dan kebijakan, serta pemanfaatan yang tepat untuk kawasan hutan mangrove yang ada di kelurahan setapuk besar, agar dapat memberikan manfaat ekologi dan ekonomi.

\section{METODE PENELITIAN}

Penelitian ini dilaksanakan di kelurahan Setapuk Besar Kecamatan Singkawang Utara Kota Singkawang Kalimantan Barat tepatnya di Jalan Ratu Sepudak RT. 02 RW. 01. Dengan lama waktu penelitian \pm 4 minggu dilapangan (25 juli-25 juni 2018). Peralatan yang digunakan antara lain; peta lokasi kamera dan panduan wawancara. Obyek dari penelitian ini adalah biaya yang dikeluarkan untuk pengayaan mangrove di Kelurahan Setapuk Besar. Penelitian ini mengunakan Teknik perhitungan yang digunakan dalam Replacement Cost berdasarkan PERMEN No 15 Tahun 2012 "Valuasi Ekonomi
Ekositem Hutan" yang sudah dikembangkan sesuai kebutuhan, yaitu: (a) Mengumpulkan semua data kegiatan yang berkaitan dengan pengembalian hutan mangrove setapuk besar. (b) Menginventarisasi faktor penunjang kegiatan pengembalain hutan mangrove yang termasuk dalam buku pembiayaan. (c) Mengumpulakan data terkait harga bibit, transpot bibit (jika dikirim dari luar Setapuk Besar), biaya penanaman, upah kerja,serta biaya yang digunakan untuk perlindungan ketika bakau yang ditananm masih kecil. (d) Mengumpulkan data mengenai biaya pembangunan tanggul beton sebagai pemecah ombak (break water) khusus daerah pesisir. (e) Membandingkan antara biaya yang digunakan untuk pengembalian hutan mangrove dan biaya untuk pembangunan tanggul beton sebagai pemecah ombak (break water). Analisis data pada penelitian ini menggunakan metode Replacement cost, dengan biaya pemulihan fisik dan pengayaan mangrove diambil sebagai ukuran manfaat minimum dan faktor yang dihitung dalam metode replacement cost: (a) biaya bibit (b) upah kerja (c) biaya persemaian (d) biaya penanaman

HASIL DAN PEMBAHASAN

KEGIATAN PENGAYAAN

Pengadaan Bibit Bakau dan
Persemaian

Pengadaan bibit dilakukan dengan mendatangkan bibit dari luar daerah Setapuk Besar misalnya dari Krimunting, Kubu Raya, Mempawah, dan daerah sambas. Kemudian bibit 
tersebut disimpan selama beberapa hari untuk menurunkan kadar gula pada buah seperti yang dikutip dalam sebuah penelitian tentang lemannya penyimpanan buah menyembabkan ketersediaan polisakarida dalam buah menurun (Helmiyesia dkk,2014).

Penyemain dilakukan dengan penyiapan polybag dan lokasi penyemaian. Menurut Jumadi Lokasi yang baik untuk penyemain berada di arel yang terlindungi sinar matahari langsung, serta dekat dengan sumber air untuk mempermudah penyiraman. Menurut Syamsuwida Dkk (2010) insensitas caya mempengaruhi laju pertumbuhan batang semangkin tinggi insesitas cahaya maka akan semangkin baik menekan pertumbuhan tinggi batang, yang artinya dengan cahaya yang intensitasnya rendah dapat membantu lajunya pertumbuhan batang. penymaian menjadi faktor penting dalam keberhasilan pengayaan, oleh karen itu perkumpulan SPM melakukan penyemaian di bawah pohon api-api (Avicenia Sp.), kondisi ini memungkinkan sebagai penganti paranet dalam pengendalian insensitas cahaya.

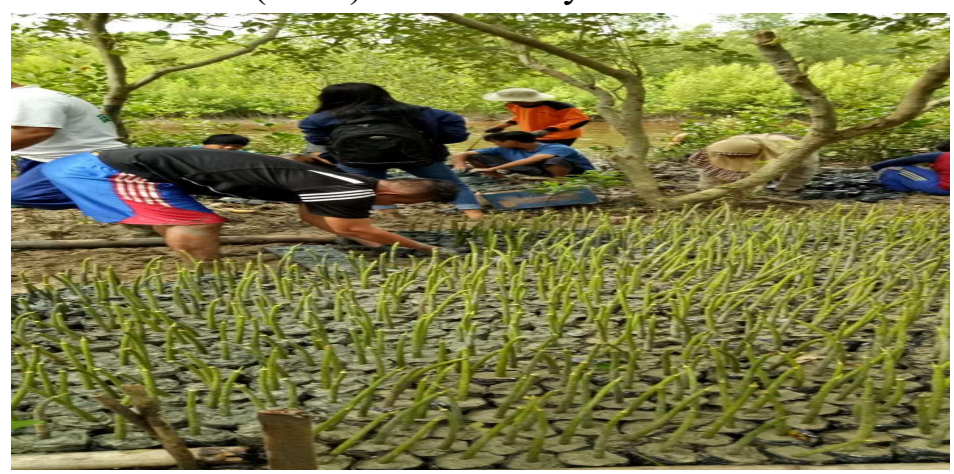

Gambar 1. Kegiatan penyemaian (seeding)

Polybag diisi lumpur yang mengandung liat yang tinggi media ini diambil dari dalam parit yang berada dekat dengan lokasi penyemaian. Kusumana (1994) bakau tumbuh dengan baik pada jenis tanah yang mempunyai kandungan liat yang tinggi (Saline Young Soil) dengan nilai kejenuhan basa dan kapasitas tukar kation yang tinggi. Menurut Whitmore (1984) dan MacKinnon dkk (1996) pada sungai-sungai besar, hutan mangrove dapat terbentuk hingga sejauh $240 \mathrm{~km}$ ke arah hulu, seperti dijumpai di sungai Kapuas, Kalimantan Barat. Jenis mangrove tumbuh dengan baik pada tanah berlumpur, terutama tanah endapan lumpur terakumulasi (Amko Dkk, 2007)

\section{Penanaman}

Penenaman bibit baku dilakukan dengan dua cara yaitu dengan cara langsung yang artinya ketika buah bakau dipanen kemudian didiamkan selama 1 minggu setelah itu langsung ditanam di lahan yang sudah disiapkan. Untuk jarak tanam ada beberapa pilihan menurut Wibisono dkk (2006) Untuk tanaman mangrove jarak tanam ideal adalah $1 \mathrm{~m} \quad \mathrm{x} \quad 1 \mathrm{~m}$ atau $1 \mathrm{~m} \quad \mathrm{x} \quad 2 \mathrm{~m}$ 
sedangkan untuk tanaman pantai yang bertajuk lebar jarak tanam ideal adalah $5 \mathrm{~m} \times 5 \mathrm{~m}$, untuk yang bertajuk kecil jarak tanam idealnya $3 \mathrm{~m} \times 3 \mathrm{~m}$ atau $4 \mathrm{~m}$ $x$ 4m. Anggota perkumpulan SPM menyepakati dengan jarak $1 \times 1$ meter, diharapakan jika bibit tumbuh dengan perakaran jangkar yang padat dapat mempercepat penambahan tinggi daratan serat presentase tumbuh lebih besar. Pada proses penanamanya menurut Pak Jumadi (2018) kedalaman pangkal bagian akar mangrove yang masuk ke dalam tanah hanya boleh sekitar 5-10 cm jika lebih dari itu maka mangrove tidak akan tumbuh dan

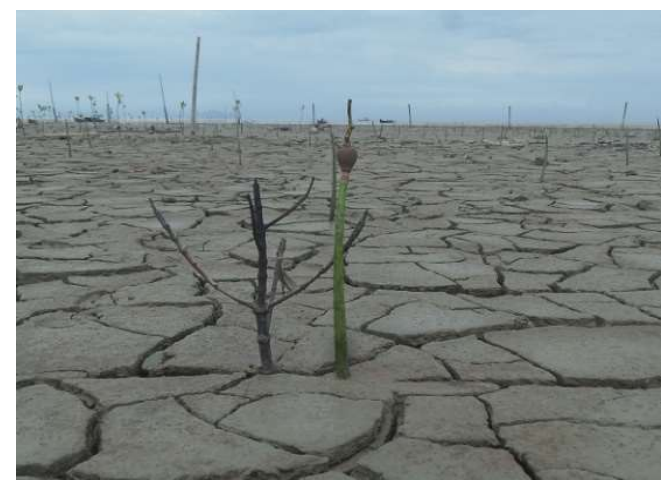

(a) kurang dari itu maka bibit akan hanyut oleh air pasang.

Cara yang berikutnya ialah dengan bibit dari semaian, pada prosesnya perkumpulan ini mengunakan teknik yang ramah lingkungan yaitu denga cara melepaskan polybag dari media tanam dengan bantuan air agar akar yang menempel pada plastik terlepas sempurana. Upaya pelepasan polybag ini dilakukan agar polybag yang berbahan plastik tidak mencemari lingkungan mengingat lamanya proses pengurain plastik oleh tanah selain itu polybag yang tadinya terbuang bisa digunakan kembali untuk penyemain selanjutnya.

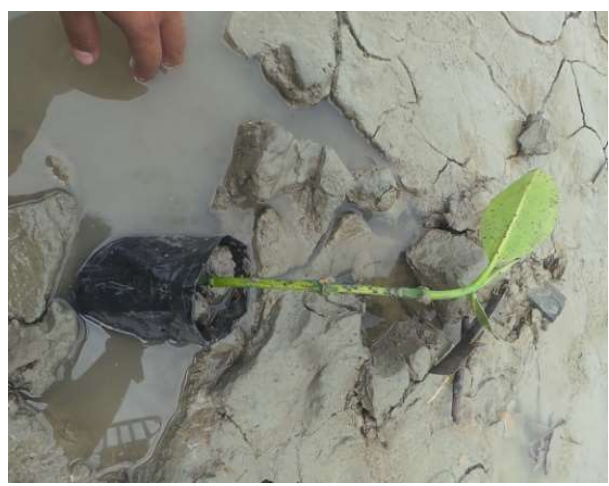

(b)

Gambar 2. Kegiatan penanaman (planting) a. Penanaman langsung (direct planting) b. penanaman tidak langsung (indirect planting)

\section{Perawatan dan Perlindungan}

Perawatan merupakan kegiatan perlindungan terhadap bibit bakau yang di tanama. Sebelum berdirinya SPM beberapa kegiatan penanaman yang pernah dilakukan oleh masayarakat Setapuk Besar namun tidak membuahkan hasil dikarenakan mangrove yang ditanam tidak dirawat. Banyak faktor yang dapat menyebakan gagalnya pertumbuhan bakau yang diantaranya Ombak, lumpur, hama, gulma dan sampah. Faktor yang paling sangat menganggu iyalah sampah dan Gulma sehingga kegiatan perawatan biasanya dilakukan tiga hingga empat kali dalam sebulan. Pada kegiatan perawatan ini ada beberapa pekerjaan yang dilakukan diantaranya, Memungut sampah, memberantas gulma, dan diselingi kegiatan penyulaman. Menurut Haryanto (2013) kegiatan perawatan 
sangat diperlukan untuk mencapai pertumbuhan mangrove yang optimal, berbagai upaya perawatan yang dapat dilakukan adalah penjarangan, penyulaman, dan membuat jaring sampah. Serata pengawasan terhadap pengunjung yang datang kegiatan ini hanya dilakukan sebatas pendekatan emosional yakni dengan melakukan teguran terhadap pelanggar (Kiolol, 2017).

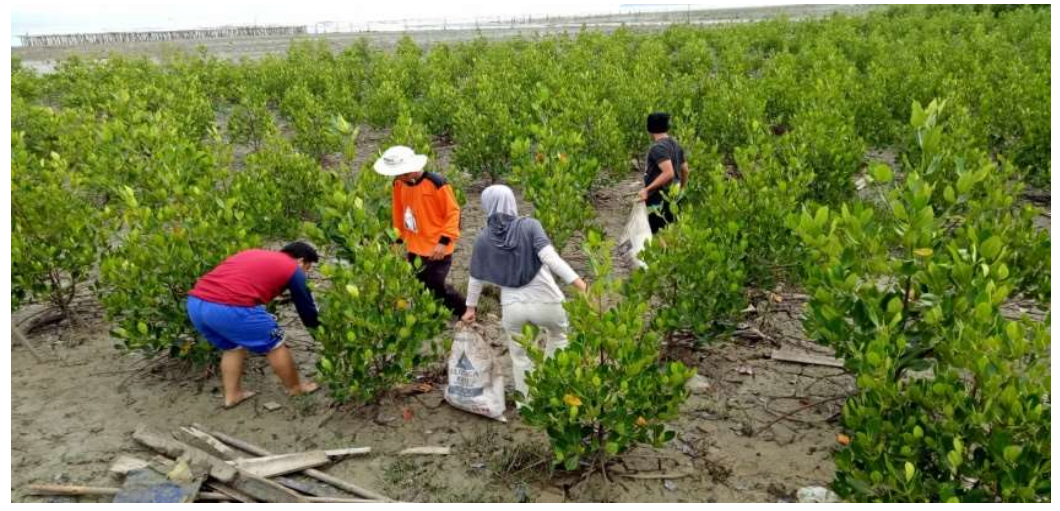

Gambar 3. Kegiatan Pemungutan sampah (cleaning the waste)

\section{Biaya Total Kegiatan Pengayaan}

Dalam penelitian ini biaya Pengayaan dibagi menjadi dua yaitu biaya tidak tetap dan biaya tetap. Biaya tetap merupakan biaya yang jumlah totalnya tetap dalam satuan dan waktu (Nugroho,2002). pada bagian biaya tetap hanya dihitung biaya penyusutasn (depresiasi) dikarenakan dalam kegiatan pengayaan di Setapuk Besar lebih cenderung pada pembiayaan tidak tetap, ada atau tidaknya variabel yang tergolong biaya tetap, kegiatan tetap akan berlangsung dikarenakan sebagian dari pekerja memiliki peralatan dan perlengkapan masing-masing. Jadi biaya kegiatan pengayaan dibedakan atas empat biaya menurut obyek pengeluaran, yaitu: biaya Penanaman (BP), biaya Perlindungan (BL), biaya Upah Kerja (UP) dan biaya invetaris (BI).

Tabel 1. Total Biaya (total costs)

\begin{tabular}{lll}
\hline No & Jenis Per-Kegiatan & Jumlah Rp. \\
\hline $\mathbf{1}$ & Penanaman & 206.912 .000 \\
$\mathbf{2}$ & Perlindungan & 46.230 .000 \\
$\mathbf{3}$ & Upah Kerja & 14.100 .000 \\
$\mathbf{4}$ & Inventaris & 2.740 .000 \\
\hline Total & & 270.182 .000 \\
\hline
\end{tabular}


Biaya pada kegiatan ini merupakan biaya yang dikeluarkan SPM untuk pengayaan dari tahun 2009-2017 dengan total Rp.270.182.000. Tahapan proses kegiatan pengayaan dimulai dari pengadaan bibit bakau (Rizhopora Mucronata dan Rizhophora Apiculata) yang dibeli dari daerah Peniti (Kabupaten Pontianak) Sungai Duri (Kabupaten Bengkayang) dan Pemangkat (Kabupaten Sambas). Sejak tahun 2009-2017 sudah ada 153.160 batang bibit yang peroleh dengan nilai yang dikeluarkan pembelian bibit sebasar Rp.45.968.000, biaya ini diasumsukan berdasarkan pendekatan harga bibit tahun 2017 yakni perbagulnya bibit dihargai Rp.300. Setelah ada bibit maka akan didiamkan selama satu minggu setelah itu beru memasuki masa penyemaian dikeluarkan untuk penyemaian sejak tahun 2009-2017 senilai Rp.15.316.000 tidak ada kriteria khusus pekerja dalam kegiatan penyemaian. Biaya penyemaian dihargai sebesar Rp.100 per polybagnya dari jumlah 153.160 bibit tidak semua bibit yang ditanam melalui proses penyemaian karena perkumpulan SPM mengunakan dua teknik penanaman yaitu penanaman langsung dan penanaman dari bibit semai. Setelah bibit tumbuh hingga berdaun 4 maka bibit sudah siap ditanam dilahan, jarak tanam yang disepakati oleh kelompok SPM adalah 1x1 m dan penanamannya tanpa mengikut sertakan polybag didalam tanah, hal ini dilakukan mengingat lamanya proses pengurain pelastik oleh tanah.

Biaya

penanaman Rp.206.912.000 dari tahun 2009-2017 bibit yang ditanam dihargai sebesar Rp.700 pertanaman dan harga ini sudah termasuk dalam harga pengangkutan bibit ke lokasi penanaman. Bibit yang sudah ditanam tidak akan selalu diperhatikan perkembanganya dalam kegiatan perawatan, perawatan dilakukan empat kali dalam sebulan dan dikerjakan oleh empat orang tenaga kerja, perharinya kegiatan perawatan dihargai sebesar Rp.50.000 kegiatan ini dimulai dari jam 07:00-11:00.

Dari hasil penelitian didapatkan total biaya dari kegiatan pengayaan di Kelurahan Setapuk Besar sebesar Rp.270.182.000. Biaya tersebut merupakan biaya yang dikeluarkan untuk kegiatan penanaman bakau serta perlindungan dan perawatan seluas 26,1 Ha jika dihitung perhektarnya maka diperoleh biaya sebesar Rp.10.229.000. Pada tahun 2010 desa Lantang Peo menyediakan areal tambak seluas $40 \mathrm{Ha}$ ditambah 6 desa lainnya dengan total luas lahan $530 \mathrm{Ha}$, untuk kegiatan Pengayaan Ekologis Mangrove dan peningkatan ekologis dibutuhkan biaya sebesar Rp. 6.203.790.000, dan Rp. 11.696.100 per Ha. Penelitian yang dilakukan oleh Brown dkk (2014) pengayaan kawasan tambak seluas 400 Ha dengan biaya USD. 590.000 atau Rp.6.873.500.000, dan Rp. 17.183.750 per Ha. Jika di perhatikan terdapat perbedaan biaya yang signifikan per $\mathrm{Ha}$ dalam kegiatan pengayaan kawasan mangrove, hal ini dikarenakan perbedaan lokasi, perencanaan, alat, dan 
sistem pengelolaannya. Pada penelitian diatas perbedaan perolehan biaya dibedakan berdasarkan pendekatan antara anggaran biaya kegiatan penanaman mangrove dan pendekatan dengan biaya pembuatan APO.

Penelitian di lapangan pengelolaan kawasan mangrove Setapuk Besar dilakukan berdasarkan Asas kekeluargaan sehingga perkumpulan ini tergolong perkumpulan yang mandiri. Berdasarkan wawancara dengan lembaga yang berperan dalam penyokong dana pada kegiatan pengelolaan mangrove Setapuk besar menurut Pak Albert Ketua WWF (2018 ) SPM merupakan kelompok yang mandiri, ada atau tidak adanya dana kelompok ini tetap dapat melaksanakan kegiatan penanaman. Selain itu tidak ada peralatan khusus dalam pengelolanya sehingga dengan dana seadanya tidak menjadi pembatas untuk kelompok ini melakukan kegiatan.

\section{Biaya Perbandingan APO dan Penanaman Mangrove}

Tabel 2. Perbandingaan manfaat APO dan penanaman mangrove (comparison the benefit APO and planting mangorve)

\begin{tabular}{|c|c|c|c|}
\hline Manfaat & Mangrove & APO Bambu & APO Beton \\
\hline Biaya & Rp. 270.182.000. & Rp.349.200.000 & RP. 834.979.200 \\
\hline Ekonomi & $\begin{array}{lll}\text { - } & \text { Ekowisata } & \\
\text { - } & \text { Penghasil pagan dan } \\
\text { papan } & \\
\text { - } & \begin{array}{l}\text { Pengembangan } \\
\text { teknologi }\end{array} & \\
& \end{array}$ & $\begin{array}{ll}\text { - } & \text { Menyerap tenaga } \\
\text { kerja } & \end{array}$ & $\begin{array}{ll}\text { menyerap } & \text { tenaga } \\
\text { kerja } & \end{array}$ \\
\hline $\begin{array}{l}\text { Biologi dan } \\
\text { fisik }\end{array}$ & $\begin{array}{ll}- & \text { Habitat fauna } \\
\text { - } & \text { Menambah } \\
& \text { permukaan } \\
\text { - } & \text { Perangkap sedimen } \\
\text { - } & \text { Biofilter alami }\end{array}$ & $\begin{array}{ll}\text { - } & \text { Tempat hidupnya } \\
\text { kerang dan Molusca } \\
\text { - } \\
\text { Memperlambat laju } \\
\text { erosi }\end{array}$ & $\begin{array}{ll}\text { - } & \text { Tempat Hidupnya } \\
\text { kerang dan Molusca } \\
\text { - } \\
\text { Memperlambat laju } \\
\text { erosi }\end{array}$ \\
\hline Sosial & $\begin{array}{ll}\text { - } & \text { Menjadi tempat } \\
& \text { berinteraksinya warga } \\
\text { - } & \text { Berolahraga } \\
\text { - } & \begin{array}{l}\text { Sarana hiburan dan } \\
\text { rekreasi }\end{array}\end{array}$ & - $\quad$ Kurang memadai & Kurang memadai \\
\hline
\end{tabular}




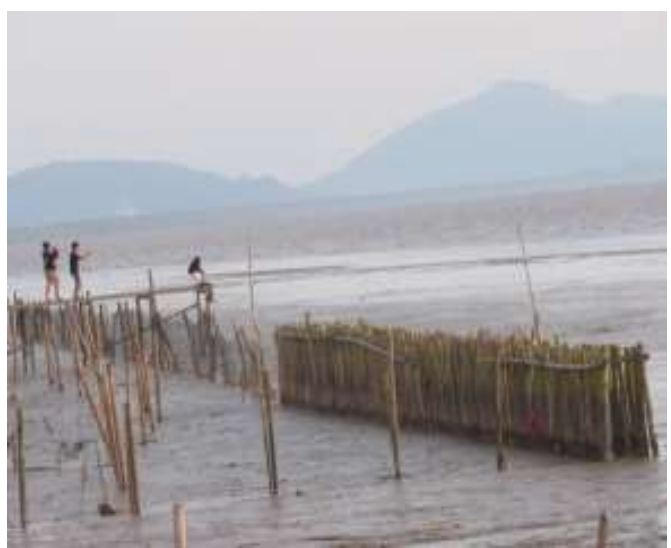

(a)

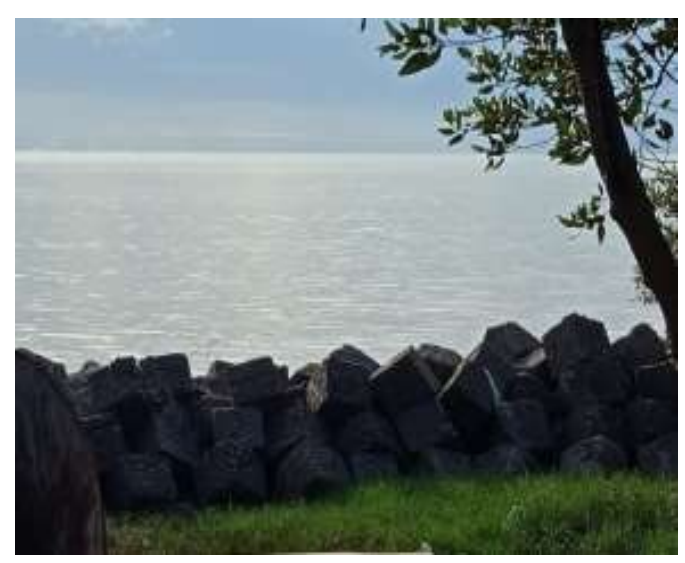

(b)

\section{Gambar 4. Alat Pemecah ombak (Breakwater) a. APO Bambu (Brush breakwater) b. APO Beton (Concrete breakwater)}

Meskipun hutan mangrove Setapuk Besar belum sepenuhnya mengembalikan barang dan jasa yang telah hilang namun dengan keberadaan mangrove Setapuk Besar saat ini membuktikan pencapaian yang memuaskan. Pencapaian tersebut diantaranya penambahan daratan sejauh kurang lebih 170 meter ke arah laut, kembalinya beberapa fauna diantaranya kepiting bakau, Kepah, burung Punai, dan menjadikan laut dipesisir mangrove sebagai tempat ikan mencari makan (feeding ground). Dengan bertambahnya daratan menciptakan kawasan mangrove Setapuk Besar sebagai prasarana untuk berkativitas dan berinteraksi, seperti berolahraga, menjadi pusat edukasi dan rekreasi.

\section{Kesimpulan}

Berdasarkan hasil penelitian mengenai valuasi dari nilai pengembalian kawasan mangrove Setapuk Besar dalam kegiatan pengayaan kawasan pesisir Setapuk Besar diperoleh kesimpulan sebagai berikut:
Kegiatan pengayaan dikelurahan Setapuk Besar diprakarsai oleh nelayan yang membentuk perkumpulan SPM, kegiatan pengayaan berlangsung dari tahun 2009 dengan menanam Jenis Rizhophora Apiculata dan Rizhophora Mucronata. Luas lahan potensial mangrove Setapuk Besar sebesar $30 \mathrm{Ha}$, namun pada tahun yang baru tertanam seluas 26,1 Ha dengan jarak tanam 1x1 namun tidak mutlak. Total biaya kegitan pengayaan di pesisisr kelurahan Setapuk Besar berdasarkan 5(lima) jenis pembiayaan diantaranya; penanaman, perawatan dan perlindungan, upah kerja, dan biaya inventaris sejumlah Rp.270.182.000, untuk biaya pembuatan tanggul pemecah ombak Rp.349.200.000, biaya penanaman mangrove jauh lebih murah dibandingkan alat pemecah ombak dikarenakan kegiatan pengayan tidak serta merta di hitung dengan uang, sikap gotong royong mendominasi dalam kegiatan pengayaan ini.

Bardasarkan manfaat yang dapat diperoleh dari kedua bentuk perlindungan 
yakni perlindungan Alami (mangrove) dan Buatan (APO). Membuktikan bahwa Menanam mangrove tidak hanya Murah dari segi biaya tetapi keberadaan mangrove dapat menciptakan dampak positif baik dari segi ekologis, ekonomi dan siosial masyarakat.

\section{Daftar Pustaka}

Brown B, Fadillah R, Nurdin Y, Soulsby I, \& Ahmad R. Community Based Ecological Mangrove Rehabilitation (CBEMR) in Indonesia. S.A.P.I.EN.S 7(2): 1-12

Harahab N.2010. Penilaian Ekonomi Ekosistem Hutan Mangrove dan Aplikasinya dalam Perencanaan Wilayah Pesisir. Jakarta: Graha Ilmu.

Haryanto A. 2013. Efektifitas Rehabilitasi Mangrove Di Pulau Pramuka Kepulauan Seribu [Thesis]. Bandung. IPB

Kiolol N, Tilaar W, RotinsuluW.2017. Pengelolaan Hutan Mangrove Berbasis Masyarakat Di Desa Kampung Ambong Kecamatan Likupang Timur

Kabupaten Minahasa Utara. AgriSosioEkonomi Unsrat 13(3A): 179 190

Kordi.2012.Ekosistem Mangrove:Potensi, fungsi, dan pengelolaan. Jakarta: Rineka Cipta.

Ronnback P.1999.The Ecological Basis for Economic Value of Seafood Production Supported by Mangrove Ecosystems. Ecological Economics 29:235-252.

.2015. Rancangan Anggaran Biaya Pembangunan Penahan Abrasi. Kabupaten Malang.

Suharti S, Darusman D, Nugroho B, Sundawati L.2015. Economic Valuation As a Basis for Sustainable Mangrove Resource Management A
Case in East Sinjai, South Sulawesi. JMHT 22(1):13-23.

Syamsuwida D, Aminah A.2010. Metode Penyimpanan Semai Bakau (Rhizopora apiculata) Dengan Berbagai Kondisi Tempat Dan Media Simpan Serta Penghambat Pertumbuhan. Jurnal Pemuliaan Tanaman Hutan 4(3):125-136

Wahyuni, Y, Putri EIK. Simanjuntak SMH.2014. Valuasi Total Ekonomi Hutan Mangrove di Kawasan Delta Mahakam Kabupaten Kutai Karta Negara Kalimantan Timur. Jurnal Penelitian Kehutanan Walacea 3(1): $1-12$

Wibisono, I.T.C, Eko B.W, I Nyoman S. 2006. Panduan Praktis Rehabilitasi Pantai; Suatu pengalaman merehabilitasi kawasan pesisir. Wetlands International Indonesia Programme. Bogor. 